\title{
Comparative observational study on the clinical presentation, intracranial volume measurements, and intracranial pressure scores in patients with either Chiari malformation Type I or idiopathic intracranial hypertension
}

\author{
Radek Frič, MD, ${ }^{1}$ and Per Kristian Eide, MD, PhD ${ }^{1,2}$ \\ 'Department of Neurosurgery, Oslo University Hospital-Rikshospitalet; and ${ }^{2}$ Faculty of Medicine, University of Oslo, Norway
}

OBJECTIVE Several lines of evidence suggest common pathophysiological mechanisms in Chiari malformation Type I (CMI) and idiopathic intracranial hypertension (IIH). It has been hypothesized that tonsillar ectopy, a typical finding in CMI, is the result of elevated intracranial pressure (ICP) combined with a developmentally small posterior cranial fossa (PCF). To explore this hypothesis, the authors specifically investigated whether ICP is comparable in $\mathrm{CMI}$ and IIH and whether intracranial volumes (ICVs) are different in patients with $\mathrm{CMI}$ and IIH, which could explain the tonsillar ectopy in CMI. The authors also examined whether the symptom profile is comparable in these 2 patient groups.

METHODS The authors identified all CMI and IIH patients who had undergone overnight diagnostic ICP monitoring during the period from 2002 to 2014 and reviewed their clinical records and radiological examinations. Ventricular CSF volume (VV), PCF volume (PCFV), and total ICV were calculated from initial MRI studies by using volumetric software. The static and pulsatile ICP scores during overnight monitoring were analyzed. Furthermore, the authors included a reference (REF) group consisting of patients who had undergone ICP monitoring due to suspected idiopathic normalpressure hydrocephalus or chronic daily headache and showed normal pressure values.

RESULTS Sixty-six patients with $\mathrm{CMI}$ and 41 with IIH were identified, with comparable demographics noted in both groups. The occurrence of some symptoms (headache, nausea, and/or vomiting) was comparable between the cohorts. Dizziness and gait ataxia were significantly more common in patients with $\mathrm{CMI}$, whereas visual symptoms, diplopia, and tinnitus were significantly more frequent in patients with $\mathrm{IIH}$. The cranial volume measurements (VV, PCFV, and ICV) of the $\mathrm{CMI}$ and IIH patients were similar. Notably, $7.3 \%$ of the $\mathrm{IIH}$ patients had tonsillar descent qualifying for diagnosis of $\mathrm{CMI}$ (that is, $>5 \mathrm{~mm}$ ). The extent of tonsillar ectopy was significantly different between the $\mathrm{CMI}$ and IIH cohorts $(p<$ 0.001 ) but also between these 2 cohorts and the REF group. Pulsatile ICP was elevated in both cohorts without any significant between-group differences; however, static ICP was significantly higher $(p<0.001)$ in the IIH group.

CONCLUSIONS This study showed comparable and elevated pulsatile ICP, indicative of impaired intracranial compliance, in both $\mathrm{CMI}$ and IIH cohorts, while static ICP was higher in the IIH cohort. The data did not support the hypothesis that reduced PCFV combined with increased ICP causes tonsillar ectopy in CMI. Even though impaired intracranial compliance seems to be a common pathophysiological mechanism behind both conditions, the mechanisms explaining the different clinical and radiological presentations of $\mathrm{CMI}$ and $\mathrm{IIH}$ remain undefined.

https://thejns.org/doi/abs/10.3171/2016.4.JNS152862

KEY WORDS Chiari malformation Type I; idiopathic intracranial hypertension; intracranial compliance; intracranial pressure; diagnostic and operative techniques

ABBREVIATIONS BMI = body mass index; $\mathrm{CMI}=$ Chiari malformation Type I; CSF = cerebrospinal fluid; $\mathrm{FMD}=$ foramen magnum decompression; ICP = intracranial pressure; ICV = intracranial volume; IIH = idiopathic intracranial hypertension; MWA = mean ICP wave amplitude; MWRT = mean wave rise time; MWRTC = MWRT coefficient; $\mathrm{PCF}=$ posterior cranial fossa; PCFV = PCF volume; REF = reference; $\mathrm{VV}=$ ventricular CSF volume.

SUBMITTED December 7, 2015. ACCEPTED April 13, 2016.

INCLUDE WHEN CITING Published online June 24, 2016; DOI: 10.3171/2016.4.JNS152862. 
$\mathrm{C}$ HIARI malformation Type I (CMI) and idiopathic intracranial hypertension (IIH), also referred to as a subset of the primary pseudotumor cerebri syndrome, ${ }^{22}$ are established clinical entities often encountered by neurologists and neurosurgeons. Chiari malformation Type I is primarily characterized by idiopathic ectopy of the cerebellar tonsils, often syringomyelia, and occasionally anomalies of the posterior cranial fossa (PCF) and the craniocervical junction, and patients present with a broad spectrum of clinical symptoms. ${ }^{33}$ The tentative treatment for symptomatic CMI is foramen magnum decompression (FMD) ${ }^{5,28,41}$ Patients with IIH typically present with headache and visual disturbances, with evidence of papilledema and high opening pressure on lumbar puncture. These symptoms occur despite the absence of radiological evidence of hydrocephalus, a negative neurological examination except for cranial nerve abnormalities, and a normal cerebrospinal fluid (CSF) composition. ${ }^{9,22}$ The treatment options in IIH are repeated lumbar tapping, weight reduction, acetazolamide, and surgical diversion of the CSF (that is, shunt surgery) or optic nerve sheath fenestration. ${ }^{8,36}$

The pathophysiological mechanisms behind CMI and IIH are still poorly understood, and current treatment strategies are rather empirical, not addressing the primary cause of the disease, which in many cases can result in treatment failure. $7,13,19,31,45$ Even though CMI and IIH differ with regard to clinical presentation, radiological findings, and treatment, common underlying mechanisms have been proposed ${ }^{6}$ based on observations that both CMI and IIH occur frequently in young, often obese women; $;, 24$ that the 2 entities share similar symptoms; ${ }^{19}$ and, most importantly, that some IIH patients present with radiological evidence of tonsillar ectopy., ${ }^{1,40}$ In addition, some investigators have described patients diagnosed with $\mathrm{CMI}$ as having IIH-like symptoms and not responding to FMD. ${ }^{19,23,39}$ However, current evidence in favor of a common pathophysiological mechanism in the 2 conditions is still weak and requires further analysis.

In this present study, we therefore wished to explore whether CMI and IIH share common pathophysiological mechanisms, as well as to verify the hypothesis that tonsillar ectopy, a typical finding in CMI, results from pathological intracranial pressure (ICP) combined with a developmentally small PCF. With improved understanding of the association between CMI and IIH, we hope to contribute to more optimal treatment strategies in these patients.

We specifically questioned whether pulsatile and static ICP are comparable and whether intracranial volumes (ICVs) are different in CMI and IIH; of particular interest, then, was the PCF volume (PCFV), which could explain the tonsillar ectopy in CMI. We also addressed whether the symptom profile is comparable in the 2 patient groups. For this purpose, we identified all CMI and IIH patients who had undergone continuous overnight diagnostic recording of static and pulsatile ICP in the Department of Neurosurgery, Oslo University Hospital-Rikshospitalet, during the period from 2002 to 2014. The symptom profile, radiological findings including measurements of ICV, and static and pulsatile ICP scores were compared between the CMI and IIH cohorts.

\section{Methods \\ Ethics Approval}

This study was approved by the Oslo University Hospital-Rikshospitalet as a quality control study. The Regional Committee for Medical and Health Research Ethics (REK) of Health Region South-East, Norway, was informed in writing and had no objections to the study. Intracranial pressure data were retrieved from the Neurovascular-Hydrocephalus Quality Register.

\section{Patient Cohorts}

We identified patients diagnosed with either CMI or IIH from the department's prospective database of ICP recordings performed in patients with various conditions related to disturbed CSF dynamics during the period from 2002 to 2014. We excluded all patients in whom ICP recording had been performed after a previous attempt at surgical treatment.

The CMI and IIH cohorts were compared with a reference (REF) group consisting of subjects who had undergone overnight diagnostic ICP recording for suspected idiopathic normal-pressure hydrocephalus or chronic daily headache, to rule out IIH without papilledema. None of the patients in the REF group had undergone surgical treatment, and their ICP scores were considered to be within normal thresholds.

\section{Assessment of Clinical Symptoms and Findings}

We retrieved information from the patients' electronic health records regarding clinical symptoms or findings as noted at the outpatient clinic and/or at admission prior to the initial diagnostic ICP recording. Treatment outcome was defined as a change in symptoms and/or findings at the latest follow-up and was divided into 2 main categories: responders (relief or improvement in symptoms and/ or findings) and nonresponders (unchanged or worsening symptoms and/or findings). However, it should be stressed that neither details on clinical treatment nor evaluation of outcome was the primary focus of this particular study.

\section{Tonsillar Ectopy and ICV Measurements: MRI Assessment}

We retrieved patients' MRI scans that had been obtained at the time of initial investigation, that is, prior to any treatment. The position of cerebellar tonsils caudal or cranial to the level of the foramen magnum was defined by the distance $(\mathrm{mm})$ of the caudal tonsillar tip on a line perpendicular to a line between the basion and opisthion (that is, foramen magnum or McRae's line) on midsagittal MRI (Fig. 1). A positive value of cerebellar ectopy means a distance caudal to McRae's line, while a negative value means a distance cranial to McRae's line. The presence of syringomyelia in CMI patients was noted. As neither CMI nor IIH patients usually have ventriculomegaly as defined by morphometric measures, we decided to measure relevant ICVs to compare these 2 cohorts. For this purpose, we used iPlan volumetric software incorporated into the neuronavigation tool (BrainLab AG). After the fusion of axial T2-weighted scans with sagittal T1-weighted scans and manually adjusted automatic delineation at 1-mm 


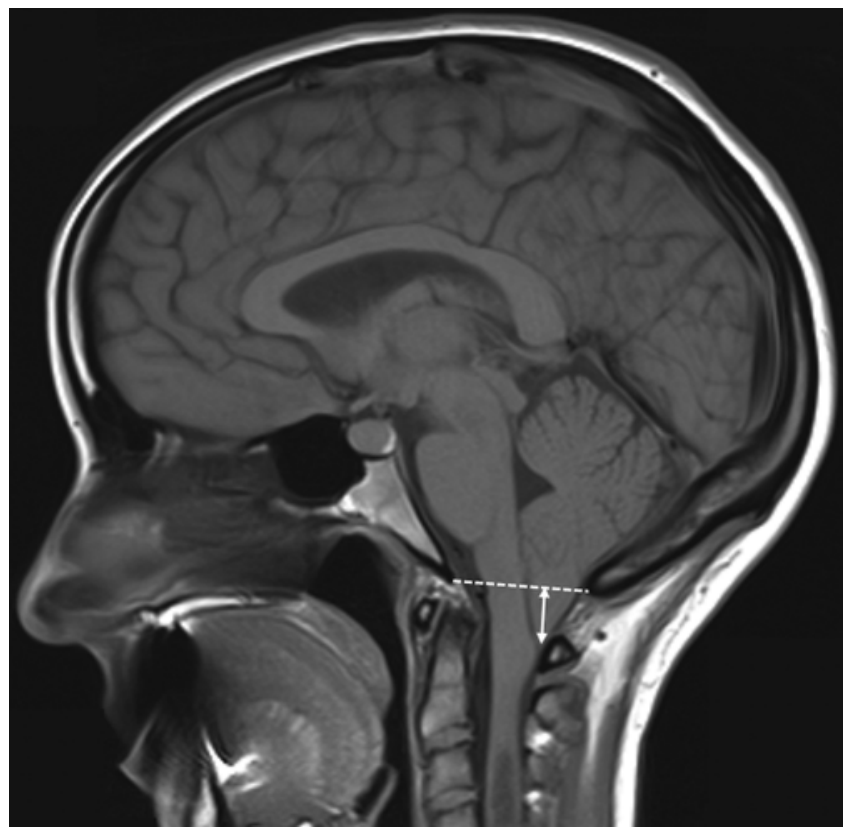

FIG. 1. The method of estimating the position of the cerebellar tonsils caudal tip above and/or below the foramen magnum line (that is, basionopisthion).

slice reconstruction, we measured the following volumes: ventricular CSF volume (VV), total ICV, and PCFV (Fig. 2). From these, we calculated a ratio between VV and ICV (VV index) and between PCFV and ICV (PCF index).

\section{Monitoring of Pulsatile and Static ICP Scores}

Diagnostic ICP monitoring was performed using a solid ICP sensor (Codman MicroSensor, Johnson \& Johnson) introduced $1-2 \mathrm{~cm}$ into the frontal brain parenchyma through a cranial bur hole under either local or occasionally general anesthesia (in children). The ICP recordings were stored as raw data files on the hospital server (sampling rate 100 or $200 \mathrm{~Hz}$ ). We used the automatic algorithm for ICP analysis incorporated into the dedicated software (Sensometrics software, dPCom AS). This algorithm computes the mean ICP during 6-second time windows independent of the ICP waveform. The ICP waveform analysis uses an algorithm for identification of the cardiac beat-induced single pressure wave, determining the amplitude (that is, difference between beginning diastolic pressure and systolic pressure) and the latency (that is, time interval from beginning diastolic pressure to systolic pressure) of the single ICP waves and then computing the pressure parameters during subsequent 6 -second time windows. Using this waveform algorithm, we determined the quality of the ICP recordings as a percentage of the 6-second time windows accepted for analysis, while the others were rejected because of artifacts in the ICP signal.

For every ICP trend plot, we computed the average values of 1) mean ICP (averaged ICP over the 6-second time window, representing the static ICP), 2) MWA (averaged ICP pulse amplitude [dP] over the 6-second time window, representing the pulsatile ICP); 3) MWRT (averaged
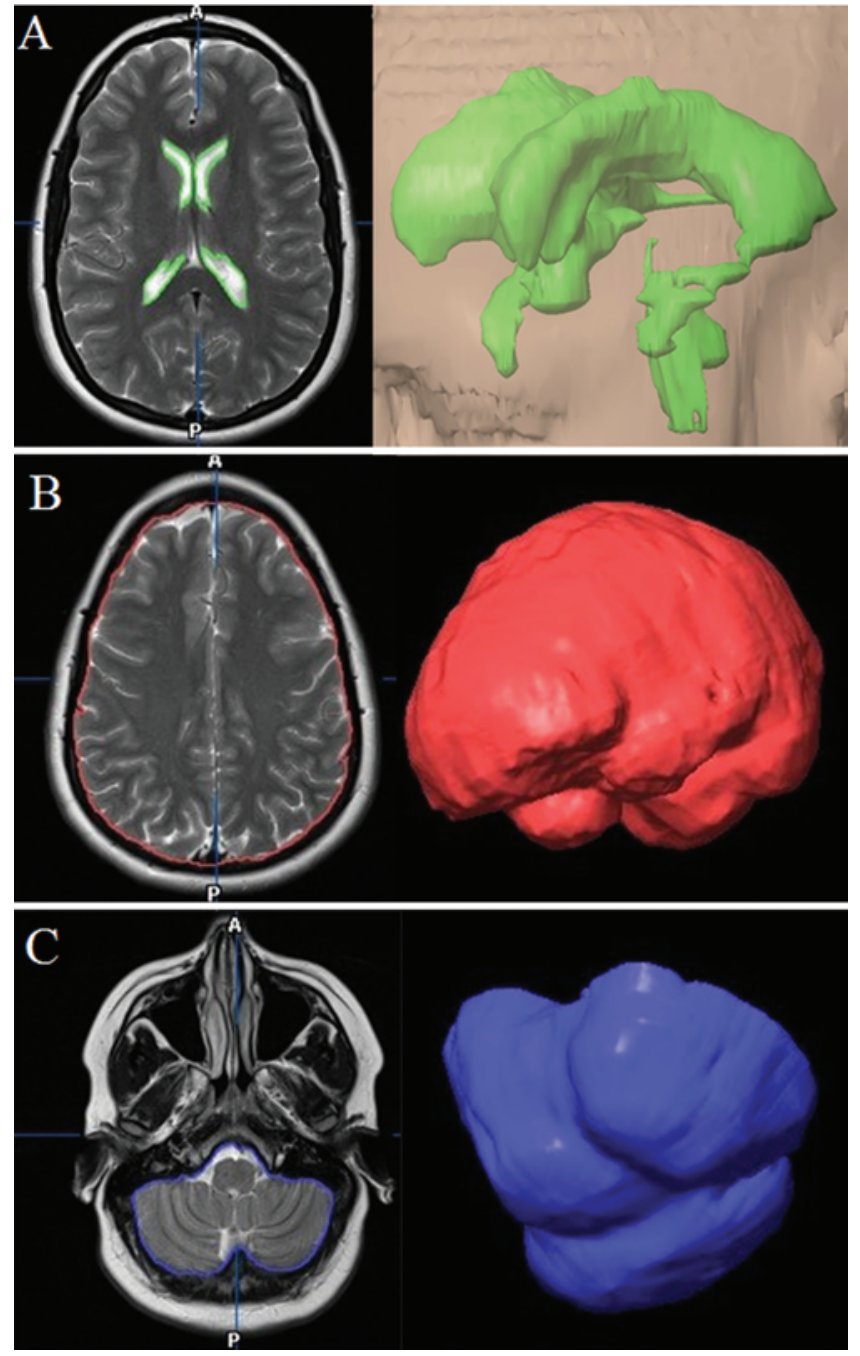

FIG. 2. Screenshots showing the method of measuring the relevant intracranial volumes from MRI using volumetric software with manually adjusted automatic delineation (iPlan, BrainLab). A: VV. B: Total ICV. C: PCFV.

pulse rise time [dT] over the 6-second time window); and 4) MWRT coefficient (MWRTC; averaged pulse rise time coefficient $[\mathrm{dP} / \mathrm{dT}]$ over the 6 -second time window). ${ }^{12}$

The pulsatile ICP was tentatively considered elevated when the average MWA was higher than $4 \mathrm{~mm} \mathrm{Hg} \mathrm{com-}$ bined with an MWA higher than $5 \mathrm{~mm} \mathrm{Hg}$ in more than $10 \%$ of the recording time. ${ }^{13,15}$ Elevated static ICP was defined as mean ICP higher than $15 \mathrm{~mm} \mathrm{Hg}$.

\section{Statistical Analysis}

All statistical analysis was performed using the Statistical Package for Social Sciences (SPSS) software, version 22.0 (IBM Corp.). The statistical significance of the differences between the cohorts was accepted at the 0.05 level.

\section{Results}

\section{Patient Cohorts}

Sixty-six patients with CMI and 41 with IIH were in- 
TABLE 1. Demographic data for the REF, CMI, and IIH patient cohorts*

\begin{tabular}{|c|c|c|c|c|}
\hline Variable & REF & $\mathrm{CMI}$ & $\mathrm{IIH}$ & $\mathrm{p}$ Value, CMI vs IIH \\
\hline No. of patients & 41 & 66 & 41 & \\
\hline Age in yrs & $46.3(42.5-49.8)$ & $29.4(25.9-33.3) \dagger$ & $27.1(22.6-31.4) \dagger$ & NS \\
\hline Sex (male/female) & $16 / 25$ & $24 / 42$ & $10 / 31$ & NS \\
\hline $\mathrm{BMl}$ in $\mathrm{kg} / \mathrm{m}^{2}$ & $26.2(24.6-27.9)$ & $25.4(23.9-27.2)$ & $28.1(25.7-30.7)$ & NS \\
\hline \multicolumn{5}{|l|}{ Treatment } \\
\hline FMD & - & $36(54.5 \%)$ & - & - \\
\hline CSF shunt & - & $4(6.1 \%)$ & $32(78.0 \%)$ & $<0.001$ \\
\hline FMD \& CSF shunt & - & $19(28.8 \%)$ & - & - \\
\hline Transection of filum terminale & - & $1(1.5 \%)$ & - & - \\
\hline Acetazolamide & - & - & $30(73.2 \%)$ & - \\
\hline Repeated lumbar tapping & - & - & $7(17.1 \%)$ & - \\
\hline Optic nerve sheath fenestration & - & - & $2(4.9 \%)$ & - \\
\hline Conservative & $41(100 \%)$ & $6(9.1 \%)$ & $1(2.4 \%)$ & NS \\
\hline FU in mos & - & $19.2(15.7-23.1)$ & $46.4(37.8-55.3)$ & $<0.001$ \\
\hline Good outcome & - & $54(87.1 \%)$ & $37(94.9 \%)$ & NS \\
\hline
\end{tabular}

FU = follow-up; NS = nonsignificant; - = not applicable.

* Continuous data are presented as the means with $95 \%$ confidence intervals in parentheses; categorical data are presented as numbers with percentages in parentheses. Significance of differences in comparisons between the 2 patient cohorts and the REF group were determined using 1-way ANOVA with Bonferroni-corrected post hoc test for continuous data and using regression analysis for categorical data. Boldface type indicates statistical significance.

$\dagger$ Significance levels for comparisons of the $\mathrm{CMI}$ and IIH cohorts relative to the REF group, $p<0.001$.

$\ddagger$ Follow-up data were only available in $62 \mathrm{CMI}$ patients and $39 \mathrm{IIH}$ patients.

cluded in the study. The REF group consisted of 41 patients under 60 years of age with suspected normal-pressure hydrocephalus (30 patients) or chronic daily headache (11 patients), in whom elevated ICP was clinically suspected but not confirmed by ICP recording. Table 1 summarizes the demographic and clinical characteristics of both patient cohorts and the REF group. The 2 patient cohorts were equal in terms of mean age and exhibited only slight differences in female predominance and body mass index (BMI).

\section{Clinical Symptoms and Findings in the $\mathrm{CMI}$ and IIH Cohorts}

Table 2 indicates a slightly different profile of symptoms in the CMI and IIH cohorts. Some symptoms were recorded in both groups; of those, headache was the most dominant symptom with almost equal occurrence in the 2 groups, followed by nausea and/or vomiting, which affected approximately one-third of the patients in each group. All of these symptoms were significantly more frequent than in the REF group. Dizziness and gait ataxia occurred significantly more often in CMI patients, whereas visual symptoms or phenomena, diplopia, and tinnitus were significantly more frequent in IIH patients.

Of those symptoms specifically observed in only 1 of the patient cohorts, neck pain and sensory symptoms from the extremities dominated among CMI patients, whereas papilledema was the most prominent finding specific to IIH patients. Of those symptoms observed in less than $10 \%$ of CMI patients, we noticed dysarthria in 5 patients (7.6\%), temperature dysesthesia in the extremities and facial numbness each in 3 patients $(4.5 \%)$, palpitations and muscle pain or seizures each in 2 patients $(3.0 \%)$, and uvula or tongue deviation, urinary incontinence, and ap- nea each in 1 patient $(1.5 \%)$. In the IIH group each of the following symptoms or signs was observed in 1 patient (2.4\%): abdominal pain, absence seizures, delayed development, macrocrania, failure to thrive, and nasal CSF leakage.

With regard to surgical treatment (Table 1), 23 (35\%) of the 66 CMI patients underwent a CSF diversional procedure (that is, shunt placement) either as a stand-alone treatment (4 patients) or in addition to FMD (19 patients). Of the 19 CMI patients treated with both FMD and CSF shunt, 12 had received the shunt first based on initial diagnostic ICP recording. The other $7 \mathrm{CMI}$ patients received the CSF shunt some time (3 days-20 months) after the FMD because of persistent symptoms of elevated (pulsatile) ICP, often documented by a new ICP recording. Follow-up data were only available for 62 of the $66 \mathrm{CMI}$ patients and 39 of the $41 \mathrm{IIH}$ patients.

\section{Tonsillar Ectopy and Cranial Volume Measures: MRI Findings}

As expected, the extent of tonsillar ectopy was significantly different between the CMI and IIH cohorts. The mean extent of ectopy of the cerebellar tonsils was 12.6 $\mathrm{mm}$ under the level of the foramen magnum in the CMI cohort, whereas tonsils laid a mean $1.7 \mathrm{~mm}$ above the foramen magnum line in the IIH cohort (Table 3). Notably, 3 (7.3\%) of $41 \mathrm{IIH}$ patients had tonsillar ectopy qualifying for a diagnosis of CMI (that is, $>5 \mathrm{~mm}$ ). The position of the cerebellar tonsils was significantly lower in both the CMI and IIH cohorts than in the REF group (Fig. 3).

We found no differences in the cranial volume measurements (VV, ICV, PCFV, or the VV as well as the PCF 
TABLE 2. Clinical symptoms and findings in the REF, CMI, and IIH cohorts*

\begin{tabular}{|c|c|c|c|c|}
\hline Parameter & REF & CMI & $\mathrm{IIH}$ & $\mathrm{p}$ Value, $\mathrm{CMI}$ vs IIH† \\
\hline No. of patients & 41 & 66 & 41 & \\
\hline \multicolumn{5}{|l|}{ Common symptoms/findings } \\
\hline Headache & $11(26.8 \%)$ & $57(86.4 \%) \ddagger$ & $35(85.4 \%) \ddagger$ & NS \\
\hline Dizziness & $2(4.9 \%)$ & $25(37.9 \%) \S$ & $7(17.1 \%)$ & 0.026 \\
\hline Gait ataxia & $29(70.7 \%)$ & $17(25.8 \%) \ddagger$ & $5(12.2 \%) \ddagger$ & 0.004 \\
\hline Cognitive deficit & $25(61.0 \%)$ & $10(15.2 \%) \ddagger$ & $5(12.2 \%) \ddagger$ & NS \\
\hline Diplopia & - & $4(6.1 \%)$ & $9(22.0 \%)$ & 0.01 \\
\hline Fatigue & $5(12.2 \%)$ & $7(10.6 \%)$ & $6(14.6 \%)$ & NS \\
\hline Nausea/vomiting & $4(9.8 \%)$ & $20(30.3 \%) \Uparrow$ & $16(39.0 \%) \S$ & NS \\
\hline Visual symptoms/phenomena & $2(4.9 \%)$ & $9(13.6 \%)$ & $28(68.3 \%) \ddagger$ & $<0.001$ \\
\hline Tinnitus & $2(4.9 \%)$ & $1(1.5 \%)$ & $8(19.5 \%)$ & 0.01 \\
\hline Syncope & - & $3(4.5 \%)$ & $3(7.3 \%)$ & NS \\
\hline Pain in extremities/trunk & - & $7(10.6 \%)$ & $1(2.4 \%)$ & NS \\
\hline \multicolumn{5}{|l|}{ Specific symptoms/findings ** } \\
\hline Paresthesias/numbness in extremities & \multicolumn{3}{|c|}{$23(34.8 \%)$} & \\
\hline Neck pain & \multicolumn{3}{|c|}{$22(33.3 \%)$} & \\
\hline Reduced strength in extremities & \multicolumn{3}{|c|}{$14(21.2 \%)$} & \\
\hline Dysphagia & \multicolumn{3}{|c|}{$8(12.1 \%)$} & \\
\hline Papilledema & \multirow{2}{*}{\multicolumn{3}{|c|}{$15(36.6 \%)$}} & \\
\hline Urinary incontinence & & & & \\
\hline \multicolumn{5}{|c|}{$\begin{array}{l}\text { * Categorical data are presented as numbers with percentages in parentheses. Boldface type indicates statistical significance. } \\
\text { † Significance of differences in comparisons between the patient cohorts were determined using regression analysis. } \\
\text { † Significance levels for comparisons of the } \mathrm{CMI} \text { and IIH cohorts relative to the REF group, } p<0.001 . \\
\S \text { Significance levels for comparisons of the } \mathrm{CMI} \text { and IIH cohorts relative to the REF group, } p<0.01 \text {. } \\
\text { I Significance levels for comparisons of the } \mathrm{CMI} \text { and IIH cohorts relative to the REF group, } p<0.05 \text {. } \\
* \text { Only symptoms or findings observed in } \geq 10 \% \text { of the patients are mentioned here; for other symptoms see text. }\end{array}$} \\
\hline
\end{tabular}

index) between the CMI and IIH cohorts, while the VV and VV index were significantly higher in the REF group than in both patient cohorts.

Syringomyelia was observed in $48.4 \%$ of CMI patients (data available for only 62 patients who had initial spinal MRI). Comparison with the IIH cohort and the REF group was not possible as only a few of the IIH and REF patients had spinal MRI.

\section{Pulsatile and Static ICP Scores in the CMI and IIH Cohorts}

The pulsatile ICP scores were comparable in the CMI and IIH cohorts and were significantly elevated in both cohorts as compared with the REF group (Table 4). On the other hand, the static ICP (mean ICP) was significantly higher $(\mathrm{p}<0.001)$ in the IIH than in the CMI cohort and the REF group. Figure 4 shows comparisons of the distribution of the pulsatile and static ICP scores between the $\mathrm{CMI}$ and IIH cohorts as well as the REF group.

\section{Association Between ICP Measures and MRI Findings}

As presented in Table 5, there was a significant positive correlation between mean ICP or MWA (that is, static and pulsatile ICP) and VV or VV index in the CMI cohort. In addition, there was a significant negative correlation between mean ICP and PCFV index, whereas this association was only close to significant for MWA. On the other hand, there was no significant correlation between the static or pulsatile ICP scores and ICV or PCFV, nor any significant association with the extent of tonsillar ectopy.

No significant association between ICP parameters and MRI findings was observed in the IIH cohort. In the REF group, there was a significant positive correlation between the extent of tonsillar ectopy and MWA.

\section{Discussion}

The main finding in the present study is the comparable and elevated pulsatile ICP, indicative of impaired intracranial compliance, in both CMI and IIH patients. We found no evidence of associated reduced ICV or PCFV as a possible cause of tonsillar ectopy in the CMI patients. To our knowledge, this is the first study to systematically compare clinical, radiological, and ICP data from patients with CMI and IIH.

\section{Patient Cohorts}

Our cohorts of CMI and IIH patients were comparable regarding sex distribution and age. Most patients were young adults, predominantly females, with a slightly higher BMI in the IIH cohort as expected since being overweight is a characteristic feature of IIH patients. 3,24,44

The scope of this work was not to evaluate the outcome of treatment in detail. Nonetheless, we noticed high rates of responders to treatment in both patient cohorts. 
TABLE 3. Radiological observations in the REF, CMI, and IIH cohorts*

\begin{tabular}{|c|c|c|c|c|}
\hline Radiological Measure & REF & $\mathrm{CMI}$ & $\mathrm{IIH}$ & $\mathrm{p}$ Value, CMI vs IIH† \\
\hline Tonsillar ectopy in mm‡ & $-5.6(-7.2$ to -3.9$)$ & $12.6(11.4-13.7) \S$ & $-1.7(-3.1$ to -0.3$) \uparrow$ & $<0.001$ \\
\hline Syringomyelia & - & $48.4 \%$ & - & - \\
\hline $\mathrm{VV}$ in $\mathrm{ml}$ & $88.8(70.2-107.2)$ & $28(23-34) \S$ & $22(19-26) \S$ & NS \\
\hline Total ICV in ml & $1518(1465-1570)$ & $1459(1426-1498)$ & $1454(1413-1494)$ & NS \\
\hline VV index $(\mathrm{VV} / \mathrm{ICV} \times 100)$ & $5.9(4.7-7.1)$ & $1.9(1.6-2.3) \S$ & $1.5(1.3-1.8) \S$ & NS \\
\hline PCFV in $\mathrm{ml}$ & $194(186-202)$ & $185(180-191)$ & $189(182-195)$ & NS \\
\hline PCFV index (PCFV/ICV × 100) & $12.8(12.4-13.2)$ & $12.7(12.4-13.0)$ & $13.0(12.7-13.3)$ & NS \\
\hline
\end{tabular}

* Data are presented as the means with 95\% confidence intervals in parentheses. Boldface type indicates significance.

$\dagger$ Significance of differences in comparisons between the patient cohorts was determined using 1-way ANOVA with Bonferroni-corrected post hoc tests.

$\ddagger$ Positive values indicate a position below the foramen magnum line, whereas negative values indicate a position above the foramen magnum line.

$\S$ Significance levels for comparisons of $\mathrm{CMI}$ and IIH cohorts relative to the REF group, $\mathrm{p}<0.001$.

I Significance levels for comparisons of $\mathrm{CMI}$ and IIH cohorts relative to the REF group, $p<0.01$.

The tendency to implant shunts in CMI patients more frequently than reported by other authors $\mathrm{s}^{5,18,25,28,29,35,42}$ reflects our practice of offering shunting to CMI patients with elevated pulsatile $\mathrm{ICP}^{20}$ prior to FMD (12 CMI patients in the present series) to prevent complications from persistent elevated ICP after FMD. ${ }^{21,45}$ Even so, another 7 patients required a shunt later ( 3 days -20 months) following FMD because of persistent and/or recurrent symptoms of elevated (pulsatile) ICP, despite satisfactory restoration of CSF pathways after FMD as documented by MRI.

More patients in the CMI group were selected for conservative treatment. This difference may be due to a usually more severe clinical presentation in IIH, requiring prompt treatment. At the same time, both $\mathrm{CMI}$ and $\mathrm{IIH}$ patients in the present study were those selected for di- agnostic ICP recording, that is, symptomatic patients who were considered candidates for treatment; thus, they may not represent the CMI or IIH populations in general.

\section{Clinical Presentation in CMI and IIH}

Analysis of the symptom profile in our cohorts of CMI and $\mathrm{IIH}$ patients revealed some similarities, while both groups naturally had specific features. The occurrence of headache and nausea and/or vomiting was comparable between the 2 cohorts. Although these symptoms may be indicative of alterations in ICP and thus reflect the impaired intracranial compliance, this association is not specific and there may be alternative causes. On the other hand, the frequency of these symptoms in the 2 patient cohorts was significantly higher than in the REF group.

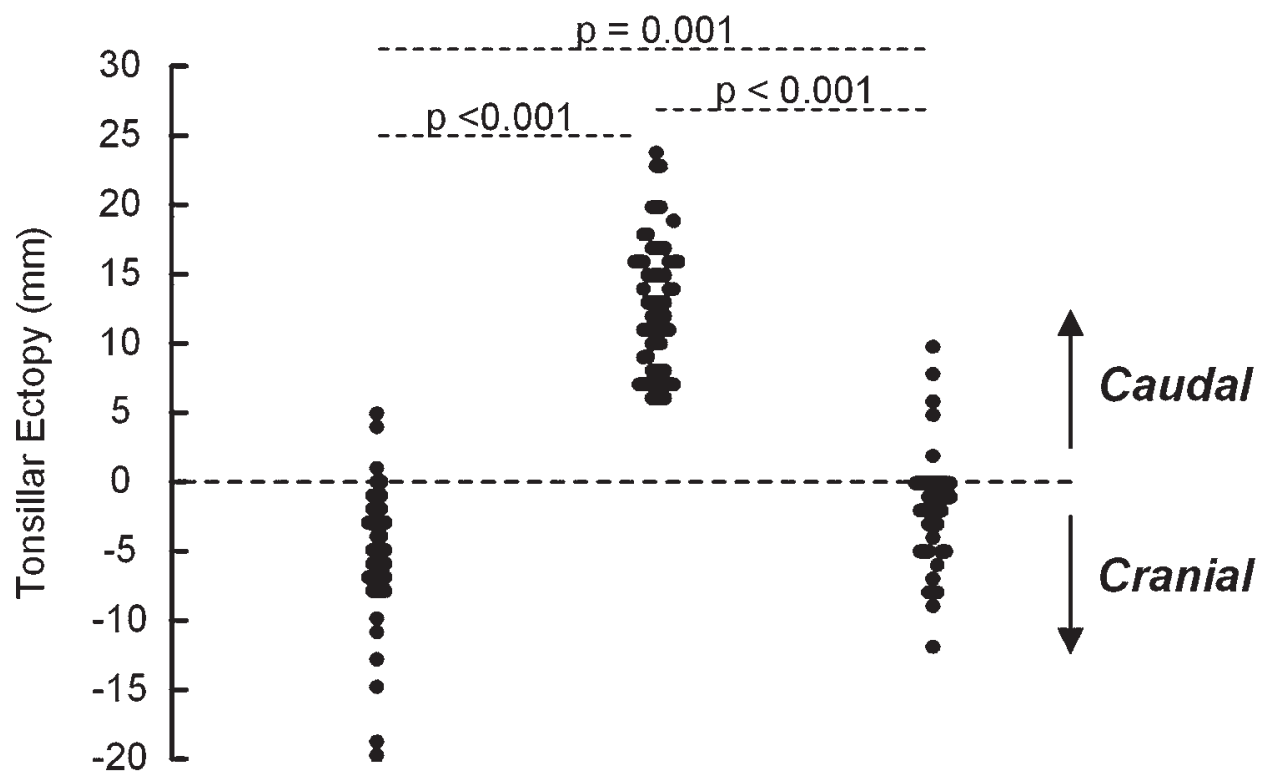

\section{REF CMI IIH}

FIG. 3. The significant difference in the extent of tonsillar ectopy between the $\mathrm{CMI}$ and IIH cohorts is demonstrated, as is the difference between the 2 patient cohorts and the REF group. Significance was determined by ANOVA with Bonferroni-corrected post hoc testing. 
TABLE 4. Pulsatile and static ICP scores in the REF, CMI, and IIH cohorts*

\begin{tabular}{|c|c|c|c|c|}
\hline Parameter & REF & $\mathrm{CMI}$ & $\mathrm{IIH}$ & $\mathrm{p}$ Value, $\mathrm{CMI}$ vs IIH $\dagger$ \\
\hline \multicolumn{5}{|l|}{ ICP wave parameters } \\
\hline \multicolumn{5}{|l|}{ MWA } \\
\hline Average in $\mathrm{mm} \mathrm{Hg}$ & $3.4(3.1-3.6)$ & $5.1(4.8-5.6) \ddagger$ & $5.7(5.1-6.3) \ddagger$ & NS \\
\hline$\% \geq 5 \mathrm{~mm} \mathrm{Hg}$ & $8(4-13)$ & $41(33-49) \ddagger$ & $52(42-61) \ddagger$ & NS \\
\hline \multicolumn{5}{|l|}{ MWRT } \\
\hline Average in sec & $0.23(0.21-0.25)$ & $0.18(0.17-0.20) \ddagger$ & $0.20(0.18-0.22) \S$ & NS \\
\hline$\% \geq 0.20 \mathrm{sec}$ & $73(62-83)$ & $41(33-50) \ddagger$ & $49(38-61) \S$ & NS \\
\hline \multicolumn{5}{|l|}{ MWRTC } \\
\hline Average in $\mathrm{mm} \mathrm{Hg} / \mathrm{sec}$ & $17.3(15.0-19.7)$ & $32.1(29.5-34.7) \ddagger$ & $33.5(29.8-37.6) \ddagger$ & NS \\
\hline$\% \geq 20 \mathrm{~mm} \mathrm{Hg} / \mathrm{sec}$ & $27(17-38)$ & $75(66-82) \ddagger$ & $80(72-88) \ddagger$ & NS \\
\hline \multicolumn{5}{|l|}{ Static ICP } \\
\hline \multicolumn{5}{|l|}{ Mean ICP } \\
\hline Average in $\mathrm{mm} \mathrm{Hg}$ & $7.5(6.2-8.8)$ & $8.8(7.6-10.0)$ & $13.8(11.5-16.0) \ddagger$ & $<0.001$ \\
\hline$\% \geq 15 \mathrm{~mm} \mathrm{Hg}$ & $6(3-10)$ & $11(6-16)$ & $39(28-51) \ddagger$ & $<0.001$ \\
\hline Quality of recording: \% accepted 6-sec time windows & $88(84-92)$ & $92(89-95)$ & $85(79-91)$ & NS \\
\hline
\end{tabular}

* Recording time from 11:00 PM to 7:00 Am. Data are presented as the means with 95\% confidence intervals in parentheses. Boldface type indicates significance.

$\dagger$ Significance of differences between patient cohorts was determined using 1-way ANOVA with Bonferroni-corrected post hoc tests.

$\ddagger$ Significance levels for comparisons of $\mathrm{CMI}$ and IIH cohorts relative to the REF group, $p<0.001$.

$\S$ Significance levels for comparisons of $\mathrm{CMI}$ and IIH cohorts relative to the REF group, $p<0.01$.

Some of the specific symptoms characterizing the CMI cohort were probably related to tonsillar ectopy into the foramen magnum. The resulting compression of long neural tracts may also explain gait ataxia, which was observed more frequently in the CMI cohort.

The high prevalence of visual disturbances, diplopia, and papilledema in the IIH group could be expected as these are characteristic findings for the condition..$^{22}$ Papilledema is typical for IIH but rare in CMI. However, it has also been reported that bilateral papilledema, as well as signs and symptoms of increased ICP, resolve after FMD in patients with IIH and documented tonsillar ectopy. $37,43,46$

Previously, several studies, most of which were case reports, pointed to the similarities in clinical presentation between CMI and IIH. ${ }^{23,26,27,30,39,40}$ Fagan et al. ${ }^{19}$ reported that 36 of 192 CMI patients did not respond with clinical improvement after FMD. Among these nonresponders, $15(41.7 \%)$ had "Chiari pseudotumor cerebri syndrome," defined by the recurrence of Chiari-like symptoms after FMD, elevated lumbar CSF pressure in the absence of ventriculomegaly, and transient resolution of symptoms with a large volume of lumbar CSF drainage. The most frequent symptoms in this subgroup were headache, body aches, and balance difficulties. Interestingly, 7 of 9 pediatric patients responded to treatment (CSF diversion), while all 6 adult patients remained variably symptomatic. Moreover, Bejjani et al., after failed FMD, successfully treated their $6 \mathrm{CMI}$ patients with CSF diversion, and they mentioned initially misdiagnosed IIH as one of the possible explanations. In the study by Zakaria et al., ${ }^{45} 12(8.7 \%)$ of 138 CMI patients still had clinical and/or radiological signs of increased ICP after FMD, $9(6.5 \%)$ of them requiring treatment. These authors interpreted the postoperative rise in ICP as a manifestation of a fundamental underlying change in CSF flow dynamics following FMD but did not specifically mention any possible association with IIH.

However, observations that some symptoms occur in both CMI and IIH patients and that some CMI patients respond to shunting rather than to FMD cannot alone be taken as proof that these conditions share common underlying pathophysiology.

\section{Radiological Findings and ICV Measurements in CMI and IIH}

Significant tonsillar ectopy can be found in some IIH patients. The incidence of asymptomatic tonsillar ectopy ( $\geq 5 \mathrm{~mm}$ ) was previously found to be $0.8 \%$ of 22,591 patients who had undergone MRI. ${ }^{32}$ In our study, $7.3 \%$ of IIH patients had tonsillar ectopy, actually qualifying them for a diagnosis of CMI. This is not far from the $10.3 \%$ found by Banik et al. ${ }^{4}$ but is much less than the rate in the radiological study by Aiken et al., who found ectopy $>5 \mathrm{~mm}$ in $20.9 \%$ of IIH patients compared with $2.3 \%$ of controls. In this latter study, IIH patients also had a significantly lower tonsillar position (mean $2.1 \pm 2.8 \mathrm{~mm}$ ) than that in agematched controls. ${ }^{1}$ This was similar to our own finding that the position of the cerebellar tonsils was significantly lower in both CMI and IIH cohorts than in the REF group. This observation suggests that tonsillar ectopy may be an epiphenomenon to elevated pulsatile ICP and impaired intracranial compliance. On the other hand, all 3 of our IIH patients with tonsillar ectopy $>5 \mathrm{~mm}$ had papilledema and responded to treatment with a CSF shunt; that is, they could be clinically considered as typical IIH patients with only coincidental asymptomatic tonsillar ectopy.

We found no evidence of differences in VV, ICV, and PCFV between the CMI and IIH cohorts. The significance of this finding is discussed below in association with ICP 
A

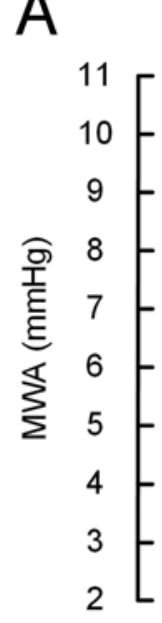

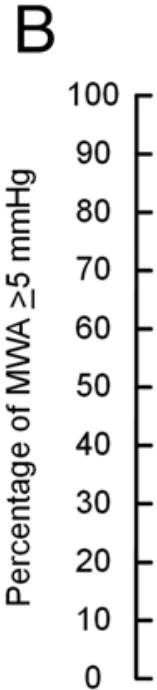

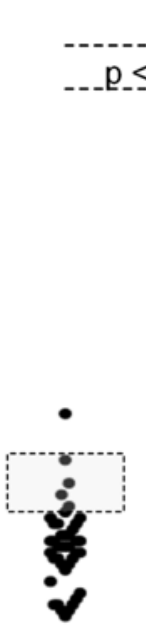

001

$\mathrm{p}<0.001$
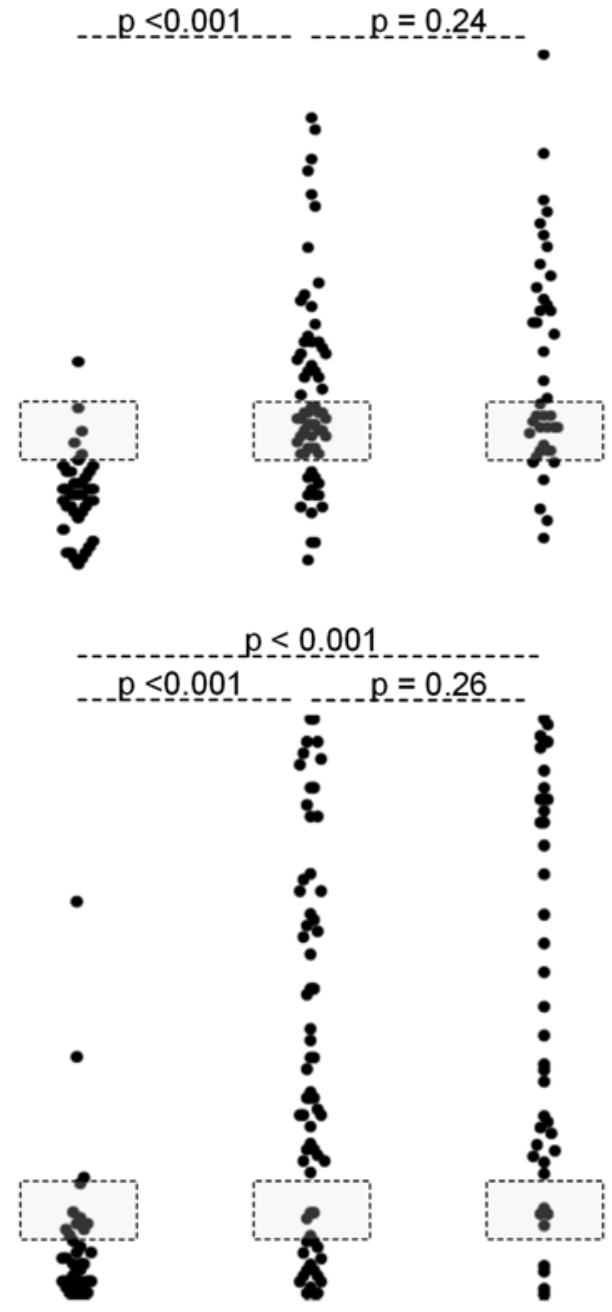

REF

IIH
C
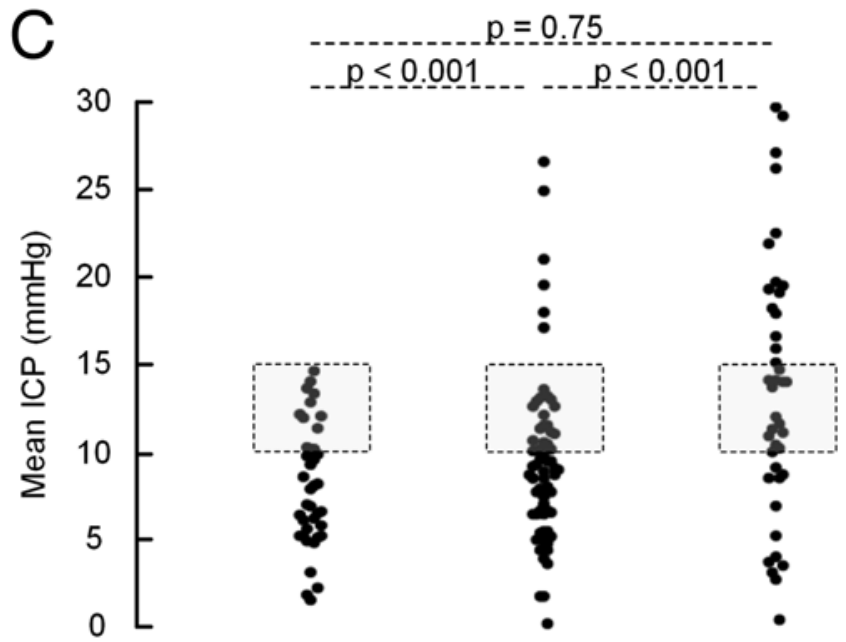

D

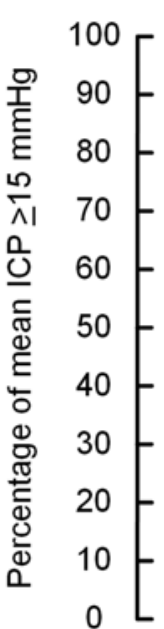

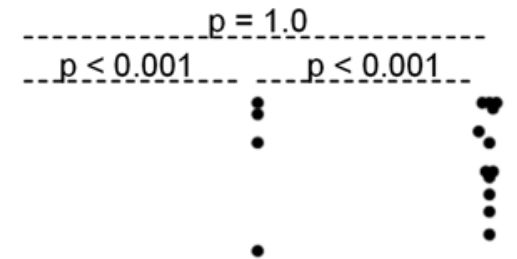

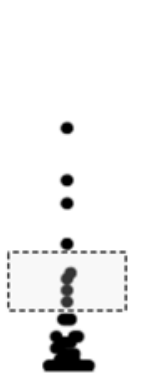

REF

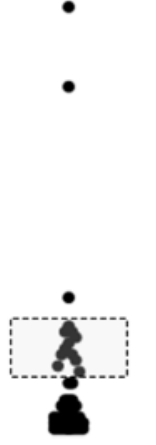

CMI

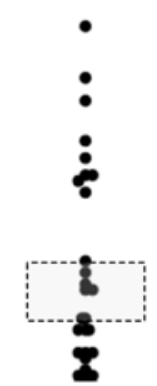

IIH

FIG. 4. For the REF, CMI, and IIH cohorts, average values of MWA (A), the percentage of MWA $\geq 5 \mathrm{~mm} \mathrm{Hg}(\mathbf{B})$, mean ICP (C), and the percentage of mean ICP $\geq 15 \mathrm{~mm} \mathrm{Hg}(D)$ are shown. Each dot represents the average value for 1 subject monitored from 11:00 PM to 7:00 AM. Dotted boxes refer to upper normal threshold areas. Significant differences were determined by ANOVA with Bonferroni-corrected post hoc testing.

scores. The significantly higher VV and VV index in the REF group were due to a higher percentage of patients with ventriculomegaly in this group, which was usually also the reason for their referral to diagnostic ICP recording.

\section{Pulsatile and Static ICP in CMI and IIH}

The present study showed comparable and elevated pulsatile ICP in both CMI and IIH patients, which supports our previous observations in these 2 patient groups. ${ }^{13,20}$ Pulsatile ICP appears to be a better indicator of the pressure-volume reserve capacity (that is, the intracranial compliance) than static ICP.11 Accordingly, we interpret our observations of elevated pulsatile ICP in both patient cohorts as evidence that impaired intracranial compliance is a common pathophysiological mechanism behind both conditions. However, this is not proof of an etiological association between CMI and IIH as we previously have reported elevated pulsatile ICP and hence impaired intracranial compliance in patients with normal-pressure hydrocephalus ${ }^{15}$ and following intracranial bleeds. ${ }^{14}$ Intracranial compliance can also be principally affected by a number of other pathological conditions of the brain.

Notably, the IIH patients had significantly higher static ICP. This fact may be associated with a poorer quality of ICP recording in this group as static ICP may be subject to baseline pressure errors. ${ }^{16,17}$ On the other hand, the elevated static ICP may indicate more severe intracranial hypertension in the IIH cohort than in the CMI cohort. In previous studies, mean ICP was found to be abnormal (that is, $>15 \mathrm{~mm} \mathrm{Hg}$ ) in $50 \%$ of IIH patients ${ }^{13}$ but in none of the CMI patients. ${ }^{20}$ 
TABLE 5. Pearson correlations between radiological measures and pulsatile or static ICP parameters in the REF, CMI, and IIH cohorts*

\begin{tabular}{|c|c|c|c|c|c|c|}
\hline \multirow[b]{2}{*}{ Parameter } & \multicolumn{2}{|c|}{ REF } & \multicolumn{2}{|c|}{$\mathrm{CMI}$} & \multicolumn{2}{|c|}{$\mathrm{IIH}$} \\
\hline & $\begin{array}{c}\text { MWA } \\
\text { (average) }\end{array}$ & $\begin{array}{l}\text { Mean ICP } \\
\text { (average) }\end{array}$ & $\begin{array}{c}\text { MWA } \\
\text { (average) }\end{array}$ & $\begin{array}{l}\text { Mean ICP } \\
\text { (average) }\end{array}$ & $\begin{array}{c}\text { MWA } \\
\text { (average) }\end{array}$ & $\begin{array}{l}\text { Mean ICP } \\
\text { (average) }\end{array}$ \\
\hline VV & $R=0.17, N S$ & $R=-0.21, N S$ & $R=0.33, p=0.006$ & $R=0.32, p=0.01$ & $R=0.29, N S$ & $R=0.13, N S$ \\
\hline ICV & $R=-0.17, N S$ & $R=0.05, N S$ & $R=0.05, N S$ & $R=0.02, N S$ & $R=0.09, N S$ & $R=-0.08, N S$ \\
\hline VV index (VV/ICV) & $R=0.20, N S$ & $R=-0.26, N S$ & $R=0.37, p=0.003$ & $R=0.34, p=0.005$ & $R=0.29, N S$ & $R=0.15, N S$ \\
\hline PCFV & $R=-0.30, N S$ & $R=0.13, N S$ & $R=-0.10, N S$ & $R=-0.21, N S$ & $R=0.08, N S$ & $R=0.07, N S$ \\
\hline PCFV index (PCFV/ICV) & $R=-0.18, N S$ & $R=0.10, N S$ & $R=-0.23, N S$ & $R=-0.34, p=0.005$ & $R=-0.01, N S$ & $R=0.17, N S$ \\
\hline Tonsillar ectopy & $R=0.34, p=0.03$ & $R=-0.08, N S$ & $R=-0.05, N S$ & $\mathrm{R}=0.16, \mathrm{NS}$ & $R=-0.05, N S$ & $\mathrm{R}=-0.27, \mathrm{NS}$ \\
\hline
\end{tabular}

* Boldface type indicates significance.

\section{Intracranial Volume Measurements Versus ICP Scores in $\mathrm{CMI}$ and IIH}

Another part of the hypothesis of a common underlying pathophysiology in CMI and IIH is the assumption that elevated ICP combined with reduced ICV and/or PCFV causes the features characteristic of CMI, particularly the tonsillar ectopy. However, one may question why only CMI patients present with tonsillar ectopy and syringomyelia if both CMI and IIH share a common pathophysiological background, while IIH patients only inconsistently exhibit some specific radiological features (empty sella, flattening of the posterior aspect of the ocular globe, distension of the perioptic subarachnoid space with or without a tortuous optic nerve, and transverse venous sinus stenosis), though unconditional for diagnosis. ${ }^{22}$ Bejjani ${ }^{6}$ suggested a common pathophysiology in the form of "craniocephalic disproportion" in which disproportion between the skull and brain can lead to CMI (due to a small skull or PCF) and/or IIH (due to an "engorged" brain), which in addition will occasionally lead to tonsillar ectopy.

The role of reduced PCFV in the pathophysiology of CMI has been widely debated and documented by many authors. ${ }^{2,10,34}$ Milhorat et al. ${ }^{34}$ even recommended the measurement of PCFV as a guide to clinical management and distinguished typical CMI with reduced PCFV from CMI with normal PCFV in which alternative mechanisms of tonsillar herniation should be investigated, raised ICP among them.

However, as recently emphasized by Roller et al., ${ }^{38}$ age, race, sex, and BMI each statistically significantly influence PCFV as well as total ICV. These authors could not find any statistically significant differences in PCFV, ICV, or the ratio between these volumes when comparing the CMI and control group after controlling for demographics, whereas patients with IIH were more likely to have a smaller PCFV and larger ICV. From our own measurements, we could conclude that there was no significant difference between the CMI and IIH cohorts in terms of VV, PCFV, and ICV. Our ICV and PCFV values correlate very well with those found by Alperin et al. ${ }^{2}$ in CMI patients, whose PCFV (184 \pm 19 vs $211 \pm 16 \mathrm{ml}, \mathrm{p}<0.001)$ as well as PCF index $(12.4 \%$ \pm 0.8 vs $14 \% \pm 0.8, \mathrm{p}<0.001)$ was significantly smaller than that in controls. From this indirect comparison, we can therefore speculate that PCFV is probably smaller in both CMI and IIH patients, although compared with our own REF group, no significant difference in PCFV was found. However, this issue appears irrelevant as there was no significant statistical correlation between PFCV and static and/or pulsatile ICP in either of our 2 cohorts.

Taken together, our findings suggest that intracranial compliance is impaired in both CMI and IIH, but they do not explain why some of the patients presented with tonsillar ectopy and/or syringomyelia (that is, CMI) while others presented with visual symptoms, papilledema, and high static ICP (that is, IIH).

In the clinical setting, this possible association between CMI and IIH is particularly important to keep in mind for CMI patients. In cases lacking a response to treatment (FMD) with symptoms indicative of persistent elevated ICP, surgical CSF diversion (that is, a shunt) must be strongly considered. Accordingly, we believe that data from the present study and the relevant literature justify the routine use of diagnostic ICP recording with analysis of the pulsatile ICP in symptomatic CMI patients who are considered candidates for surgical treatment. For the patients diagnosed with IIH, significant tonsillar ectopy must be ruled out by MRI prior to any diagnostic and/or therapeutic lumbar puncture with tapping of the CSF. As elevated static ICP appears to be a specific finding for the IIH group, it may be a certain clinical indicator of the need for CSF diversion in cases of diagnostic doubt between $\mathrm{CMI}$ and IIH.

\section{Conclusions}

This study shows comparable and elevated pulsatile ICP, indicative of impaired intracranial compliance, in both CMI and IIH patients, whereas static ICP is higher in IIH patients. The present data do not support the hypothesis that reduced PCFV combined with increased ICP causes tonsillar ectopy in CMI. Even though impaired intracranial compliance seems to be a common pathophysiological mechanism behind both conditions, mechanisms explaining the different clinical presentations of CMI and IIH remain undefined.

\section{Acknowledgments}

We thank Mr. Matthew Spreadbury for kindly reviewing the text of the manuscript.

\section{References}

1. Aiken AH, Hoots JA, Saindane AM, Hudgins PA: Incidence 
of cerebellar tonsillar ectopia in idiopathic intracranial hypertension: a mimic of the Chiari I malformation. AJNR Am J Neuroradiol 33:1901-1906, 2012

2. Alperin N, Loftus JR, Oliu CJ, Bagci AM, Lee SH, ErtlWagner B, et al: Magnetic resonance imaging measures of posterior cranial fossa morphology and cerebrospinal fluid physiology in Chiari malformation type I. Neurosurgery 75:515-522, 2014

3. Ball AK, Clarke CE: Idiopathic intracranial hypertension. Lancet Neurol 5:433-442, 2006

4. Banik R, Lin D, Miller NR: Prevalence of Chiari I malformation and cerebellar ectopia in patients with pseudotumor cerebri. J Neurol Sci 247:71-75, 2006

5. Batzdorf U, McArthur DL, Bentson JR: Surgical treatment of Chiari malformation with and without syringomyelia: experience with 177 adult patients. J Neurosurg 118:232-242, 2013

6. Bejjani GK: Association of the adult Chiari malformation and idiopathic intracranial hypertension: more than a coincidence. Med Hypotheses 60:859-863, 2003

7. Bejjani GK, Cockerham KP, Rothfus WE, Maroon JC, Maddock M: Treatment of failed adult Chiari MALFORmation decompression with CSF drainage: observations in six patients. Acta Neurochir (Wien) 145:107-116, 2003

8. Biousse V, Bruce BB, Newman NJ: Update on the pathophysiology and management of idiopathic intracranial hypertension. J Neurol Neurosurg Psychiatry 83:488-494, 2012

9. Bruce BB, Biousse V, Newman NJ: Update on idiopathic intracranial hypertension. Am J Ophthalmol 152:163-169, 2011

10. Dagtekin A, Avci E, Kara E, Uzmansel D, Dagtekin O, Koseoglu A, et al: Posterior cranial fossa morphometry in symptomatic adult Chiari I malformation patients: comparative clinical and anatomical study. Clin Neurol Neurosurg 113:399-403, 2011

11. Eide PK: The correlation between pulsatile intracranial pressure and indices of intracranial pressure-volume reserve capacity: results from ventricular infusion testing. J Neurosurg [epub ahead of print February 26, 2016. DOI: 10.3171/2015.11.JNS151529]

12. Eide PK: A new method for processing of continuous intracranial pressure signals. Med Eng Phys 28:579-587, 2006

13. Eide PK, Kerty E: Static and pulsatile intracranial pressure in idiopathic intracranial hypertension. Clin Neurol Neurosurg 113:123-128, 2011

14. Eide PK, Sorteberg W: Association among intracranial compliance, intracranial pulse pressure amplitude and intracranial pressure in patients with intracranial bleeds. Neurol Res 29:798-802, 2007

15. Eide PK, Sorteberg W: Diagnostic intracranial pressure monitoring and surgical management in idiopathic normal pressure hydrocephalus: a 6 -year review of 214 patients. Neurosurgery 66:80-91, 2010

16. Eide PK, Sorteberg A, Meling TR, Sorteberg W: Baseline pressure errors (BPEs) extensively influence intracranial pressure scores: results of a prospective observational study. Biomed Eng Online 13:7, 2014

17. Eide PK, Sorteberg A, Meling TR, Sorteberg W: The effect of baseline pressure errors on an intracranial pressurederived index: results of a prospective observational study. Biomed Eng Online 13:99, 2014

18. Ellenbogen RG, Armonda RA, Shaw DW, Winn HR: Toward a rational treatment of Chiari I malformation and syringomyelia. Neurosurg Focus 8(3):E6, 2000

19. Fagan LH, Ferguson S, Yassari R, Frim DM: The Chiari pseudotumor cerebri syndrome: symptom recurrence after decompressive surgery for Chiari malformation type I. Pediatr Neurosurg 42:14-19, 2006

20. Frič R, Eide PK: Comparison of pulsatile and static pressures within the intracranial and lumbar compartments in patients with Chiari malformation type 1: a prospective observational study. Acta Neurochir (Wien) 157:1411-1423, 2015

21. Frič R, Eide PK: Perioperative monitoring of pulsatile and static intracranial pressure in patients with Chiari malformation type 1 undergoing foramen magnum decompression. Acta Neurochir (Wien) 158:341-347, 2016

22. Friedman DI, Liu GT, Digre KB: Revised diagnostic criteria for the pseudotumor cerebri syndrome in adults and children. Neurology 81:1159-1165, 2013

23. Furtado SV, Visvanathan K, Reddy K, Hegde AS: Pseudotumor cerebri: as a cause for early deterioration after Chiari I malformation surgery. Childs Nerv Syst 25:1007-1012, 2009

24. Giuseffi V, Wall M, Siegel PZ, Rojas PB: Symptoms and disease associations in idiopathic intracranial hypertension (pseudotumor cerebri): a case-control study. Neurology 41:239-244, 1991

25. Hayhurst C, Osman-Farah J, Das K, Mallucci C: Initial management of hydrocephalus associated with Chiari malformation Type I-syringomyelia complex via endoscopic third ventriculostomy: an outcome analysis. J Neurosurg 108:1211-1214, 2008

26. Istek S: Chiari type 1 malformation in a pseudotumour cerebri patient: is it an acquired or congenital Chiari malformation? BMJ Case Rep 2014:bcr2013201845, 2014

27. Kandasamy J, Kneen R, Gladstone M, Newman W, Mohamed T, Mallucci C: Chiari I malformation without hydrocephalus: acute intracranial hypertension managed with endoscopic third ventriculostomy (ETV). Childs Nerv Syst 24:14931497, 2008

28. Klekamp J: Surgical treatment of Chiari I malformationanalysis of intraoperative findings, complications, and outcome for 371 foramen magnum decompressions. Neurosurgery 71:365-380, 2012

29. Kumar R, Kalra SK, Vaid VK, Mahapatra AK: Chiari I malformation: surgical experience over a decade of management. Br J Neurosurg 22:409-414, 2008

30. Kurschel S, Maier R, Gellner V, Eder HG: Chiari I malformation and intra-cranial hypertension: a case-based review. Childs Nerv Syst 23:901-905, 2007

31. McGirt MJ, Woodworth G, Thomas G, Miller N, Williams M, Rigamonti D: Cerebrospinal fluid shunt placement for pseudotumor cerebri-associated intractable headache: predictors of treatment response and an analysis of long-term outcomes. J Neurosurg 101:627-632, 2004

32. Meadows J, Kraut M, Guarnieri M, Haroun RI, Carson BS: Asymptomatic Chiari Type I malformations identified on magnetic resonance imaging. J Neurosurg 92:920-926, 2000

33. Milhorat TH, Chou MW, Trinidad EM, Kula RW, Mandell M, Wolpert C, et al: Chiari I malformation redefined: clinical and radiographic findings for 364 symptomatic patients. Neurosurgery 44:1005-1017, 1999

34. Milhorat TH, Nishikawa M, Kula RW, Dlugacz YD: Mechanisms of cerebellar tonsil herniation in patients with Chiari malformations as guide to clinical management. Acta Neurochir (Wien) 152:1117-1127, 2010

35. Navarro R, Olavarria G, Seshadri R, Gonzales-Portillo G, McLone DG, Tomita T: Surgical results of posterior fossa decompression for patients with Chiari I malformation. Childs Nerv Syst 20:349-356, 2004

36. Piper RJ, Kalyvas AV, Young AM, Hughes MA, Jamjoom AA, Fouyas IP: Interventions for idiopathic intracranial hypertension. Cochrane Database Syst Rev 8:CD003434, 2015

37. Rigamonti A, Lauria G, Mantero V, Piamarta F, Parolin M, Salmaggi A: A case of papilloedema associated with Chiari I malformation. J Neurol Sci 353:183-184, 2015

38. Roller LA, Bruce BB, Saindane AM: Demographic confounders in volumetric MRI analysis: is the posterior fossa 
really small in the adult Chiari 1 malformation? AJR Am J Roentgenol 204:835-841, 2015

39. Schmitt M, Kiefer M, Antes S, Eymann R: Detection of hidden pseudotumour cerebri behind Chiari 1 malformation: value of telemetric ICP monitoring. Childs Nerv Syst 28:1811-1813, 2012

40. Sinclair N, Assaad N, Johnston I: Pseudotumour cerebri occurring in association with the Chiari malformation. J Clin Neurosci 9:99-101, 2002

41. Sindou M, Gimbert E: Decompression for Chiari type Imalformation (with or without syringomyelia) by extreme lateral foramen magnum opening and expansile duraplasty with arachnoid preservation: comparison with other technical modalities (Literature review). Adv Tech Stand Neurosurg 34:85-110, 2009

42. Tisell M, Wallskog J, Linde M: Long-term outcome after surgery for Chiari I malformation. Acta Neurol Scand 120:295-299, 2009

43. Vaphiades MS, Eggenberger ER, Miller NR, Frohman L, Krisht A: Resolution of papilledema after neurosurgical decompression for primary Chiari I malformation. Am J Ophthalmol 133:673-678, 2002

44. Wall M, Kupersmith MJ, Kieburtz KD, Corbett JJ, Feldon SE, Friedman DI, et al: The idiopathic intracranial hypertension treatment trial: clinical profile at baseline. JAMA Neurol 71:693-701, 2014

45. Zakaria R, Kandasamy J, Khan Y, Jenkinson MD, Hall SR, Brodbelt A, et al: Raised intracranial pressure and hydrocephalus following hindbrain decompression for Chiari I malformation: a case series and review of the literature. Br $\mathbf{J}$ Neurosurg 26:476-481, 2012

46. Zhang JC, Bakir B, Lee A, Yalamanchili SS: Papilloedema due to Chiari I malformation. BMJ Case Rep 2011:bcr0820114721, 2011

\section{Disclosures}

Dr. Frič reports no conflict of interest concerning the materials or methods used in this study or the findings specified in this paper. The software used for analysis of the ICP recordings (Sensometrics software) is manufactured by a software company (dPCom AS) in which Dr. Eide has a financial interest.

\section{Author Contributions}

Conception and design: both authors. Acquisition of data: both authors. Analysis and interpretation of data: both authors. Drafting the article: Frič. Critically revising the article: Eide. Reviewed submitted version of manuscript: both authors. Approved the final version of the manuscript on behalf of both authors: Frič. Statistical analysis: Eide.

\section{Correspondence}

Radek Frič, Department of Neurosurgery, Oslo University Hospital-Rikshospitalet, PO Box 4950, Nydalen, Oslo 0424, Norway. email: radek.fric@medisin.uio.no. 